\title{
Tuberculosis: cost of illness in Germany
}

\author{
Roland Diel*, Stefan Rutz ${ }^{\#}$, Stefanie Castell ${ }^{\top}$ and Tom Schaberg ${ }^{+}$
}

ABSTRACT: 4,444 new cases of tuberculosis (TB) were reported in Germany in 2009; of those, the proportion of multidrug-resistant (MDR)-TB cases increased to $2.1 \%$ (63 cases).

On the basis of the therapy guidelines of the German Central Committee against Tuberculosis and the new World Health Organization guidelines, this study estimates the mean direct outpatient and combined in- and outpatient costs of TB, together with other attributable costs of the disease on the basis of the most recent German official health statistics and scientific literature.

According to this, the mean outpatient costs (rounded) per case were $€ 1,197$ (adults) and $€ 1,006$ (children) for standard therapy, but $€ 36,543$ for treatment of MDR-TB. The mean combined in-patient/outpatient costs were $€ 7,364$ (adults) and $€ 7,300$ (children), respectively; the combined costs for treatment of MDR-TB amounted to $€ 52,259$. Including MDR-TB cases the mean costs of treatment per TB case were $€ 7,931$. These are joined by the mean costs due to loss of productivity $(€ 2,313)$, costs per case for rehabilitation (€74) and contact tracing (€922), adding up to $€ 11,240$.

When considering the probability of increasing numbers of MDR-TB cases in the near future, TB is still a disease of significant economic impact in Germany.

KEYWORDS: Cost analysis, diagnostic procedures, guidelines, multidrug-resistant tuberculosis, therapy

$\mathrm{t}$ has become almost a strict convention that original articles on tuberculosis (TB) begin with the statement that TB is still the world's most frequent contagious disease, causing $\sim 1.5$ million deaths in 2010, with $>8$ million people contracting the disease every year according to the World Health Organization (WHO) [1]. Globally, in 2010, just over 46,000 patients of multidrugresistant (MDR)-TB were enrolled in treatment [2]. Thus, from a health economics point of view, the prevalence of the disease, estimated to be 12 million cases in 2010 [1], is associated with considerable socioeconomic problems.

Since a first cost calculation arising for a "typical" pulmonary TB patient in 2001 in Germany was made [3], the official number of new cases of TB in Germany has decreased from 7,539 to a total number of 4,444 reported cases in 2009 [4]. That relatively modest number fails, however, to indicate the economic burden that TB places on the health system. 7 yrs have elapsed since the publication of our work and today an up-to-date, more comprehensive cost-of-illness study, now also addressing the costs of MDR-TB, is overdue. In its aim to provide a realistic report of the current morbidity costs for TB in Germany, the present update on this subject extends the scope to a societal point of view and includes all types of TB, not only that affecting the lungs.

\section{METHODS}

This analysis considers only costs that are legally mandated to or are due to procedures representing the "state of the art" of therapy. Because they cannot be adequately modelled, some costs that may arise from cases of $\mathrm{TB}$ are not taken into consideration. For example, the cost of chemoprevention in people exposed to $\mathrm{TB}$ patients is dependent on individual decisions and unclear adherence patterns, making meaningful modelling impossible.

From a societal point of view, the following cost categories were defined and calculated, where possible, based on the most recent available data in each case. 1) Costs for diagnosis and therapy of TB borne by the state health insurance system $(\mathrm{GKV}) ; 2)$ costs incurred by public health units for execution of contact investigations as required

For editorial comments see page 9.

This article has supplementary material available from www.erj.ersjournals.com

Earn CME accreditation by answering questions about this article. You will find these at the back of the printed copy of this issue or online at www.erj.ersjournals.com/site/misc/cmeinfo.xhtml
AFFILIATIONS

*Dept for Pneumology, Medical School Hannover, Hannover,

${ }^{\text {\#}}$ Dept for Hospital Care and Rehabilitation, Barmer GEK Public Health Insurance, Mannheim,

-German Central Committee Against Tuberculosis, Berlin, and ${ }^{+}$Center of Pneumology, Deaconess Hospital Rotenburg, Rotenburg, Germany

CORRESPONDENCE

R. Diel

Dept of Pneumology

Medical School Hannover

Carl-Neuberg-Str. 1

30625 Hannover

Germany

E-mail: Diel.Roland@mh-

hannover.de

Received:

Nov 222011

Accepted after revision:

Dec 242011

First published online:

Jan 202012 
by the Federal Law on Infectious Diseases; 3) costs incurred through rehabilitation borne by German pension insurance; 4) indirect costs due to loss of productivity on the part of the general economy; 5) costs for productivity losses caused by deaths; and 6) intangible costs.

Our calculations of the direct costs are based on the rates established by the uniform appraisal scale (EBM) [5] and Institute for the Hospital Remuneration System (InEK) data [6, 7] for the German diagnosis-related groups (DRG) system; these constitute the costs effectively incurred by the GKV. Specifically, we used data provided by the Barmer-GEK Krankenkasse (Barmer-GEK health insurance institute) as the basis for a special evaluation of daily reimbursement costs to the GKV for patients hospitalised for $>14$ days.

Given that no representative random sampling study of the number of workdays lost due to TB in Germany (International Classification of Disease (ICD)-10 A15-A19) exists, calculation of the indirect costs is simplified by taking the latest available sick leave period (in 2009) for gainfully employed compulsory members of the AOK, which is the statutory health insurance fund with the largest number of members in Germany [8]. It is not possible to say how representative the AOK patient contingent is for all people insured in the GKV. Given, however, the AOK's large share of coverage throughout Germany, the probable deviations are likely to be negligible.

Loss of productivity from the point of view of the general economy is then calculated on the basis of the gainfully employed rate (the share of 15-65-yr-olds in the country's population that are gainfully employed).

The basic presumptions for the cost calculations stated below are based strictly on the new joint guidelines of the German Central Committee against Tuberculosis (DZK) and the German Respiratory Society for TB therapy [9], who adopted the new WHO guidelines on therapy for MDR-TB [10].

\section{Epidemiological background}

Since the last German cost of burden analysis for TB [3] was published, epidemiological data as well as cost figures have changed remarkably. In Germany, for 2009, the Robert Koch Institute in Berlin was notified of a total of 4,444 TB cases, generating a TB incidence rate of 5.4 cases per 100,000 population [4]. Only 146 new cases were reported in children, so the large majority of cases $(96.7 \%)$ was in adults (defined as $\geqslant 15$ yrs of age [11]). Treatment in hospital wards or special lung hospitals occurred in $71.2 \%$ of the 4,444 TB cases, followed up by physicians in private practice.

In adults, $80.2 \%$ of the cases were pulmonary TB, and 3,150 $(80.5 \%)$ of 3,913 TB cases for whom a culture was performed (independent of the specimen investigated) were culturepositive. In 231, 5.5\% of the 4,201 adult patients, for whom organ manifestations were reported, TB cases were by definition extrapulmonary, but intrathoracic.

The proportion of MDR-TB increased from $1.6 \%$ (49 cases) in 2008 to $2.1 \%$ (63 cases) in 2009 of the 2,989 cases for whom information on strain resistance was reported, or $1.4 \%$ of all reported 4,444 TB cases. Of the 63 MDR patients, 46 were treated in hospital $(73.0 \%)$ for a mean duration of 86.36 days (B. Brodhun, Robert Koch Institute, Berlin, Germany; personal communication), of whom all but one (with 9 days hospital treatment) were hospitalised for $>14$ days.

\section{Diagnosis and therapy}

The diagnostic algorithm for TB is largely defined by the catalogue of procedures for which the GKV will pay. Currently, these begin with a tuberculin skin test (TST) according to Mendel-Mantoux to verify infection (payment by the GKV for the use of the more specific interferon- $\gamma$ release assays is still restricted to persons screened for latent TB prior to administration of tumour necrosis factor- $\alpha$ inhibitors or in HIV-positive patients). In patients with suspected pulmonary TB, this is generally followed by a chest radiograph (of the affected organ) and bacteriological confirmation, usually from sputum or bronchoalveolar lavage following referral to a pneumologist, with microscopic verification of acid-fast bacillus (indicator of contagiousness) and/or culture (pathogen verification) together with a sensitivity test of the first isolate for anti-TB chemotherapy drugs. In any case of suspected TB, including suspected extrapulmonary TB involving other (nonlung) specialists, nucleic acid amplification test assays should in addition be performed routinely for rapid identification of the Mycobacterium tuberculosis complex or for MDR, e.g. by GeneXpert $\mathbb{R}$ (Cepheid, Sunnyvale, CA, USA), detecting rifampicin (R)resistance in sputum samples and other body fluids, especially in patients from MDR high-burden countries and in patients with known previous contact with a MDR-TB case.

According to the guidelines of the DZK [9], a therapy regimen that keeps recurrence rates at a minimum (3\%) for lung TB and also for all extrapulmonary varieties of TB disease (apart from TB of the CNS) lasts at least 6 months. In view of the fact that, in Germany, $11.4 \%$ of all culturally verified cases of TB are resistant to at least one of the first-line drugs, the quadruple combination of isoniazid $(\mathrm{H}), \mathrm{R}$, pyrazinamide $(\mathrm{Z})$ and ethambutol (E) is recommended. After a so-called initial phase of 2 months that precedes the arrival of the resistance results, in the subsequent continuity phase, patients with fully sensitive strains are then treated with $\mathrm{H}$ and $\mathrm{R}$ for a further 4 months. In children only, an initial phase with three drugs $(\mathrm{H}, \mathrm{R}$ and $\mathrm{Z})$ is necessary if there are no risk factors for resistance (prior treatment, etc.). This combination can be used because, in children, colonisation is relatively limited and consequently the probability of spontaneous resistance mutations is very low. Drug-resistant TB in children is a rare exception in Germany.

Basically, although therapy of MDR-TB (at least resistance against $\mathrm{H}$ and $\mathrm{R}$ simultaneously) is complex and, in exceptional cases, highly individual, the WHO has proposed a fixed regimen schedule combination that should include at least $\mathrm{Z}$ added to a minimum of four second-line anti-TB drugs that are likely to be effective: a fluoroquinolone, a parenteral agent (kanamycin, amikacin or capreomycin), ethionamide (or prothionamide), and either cycloserine or $p$-aminosalicylic acid (PAS) if cycloserine cannot be used.

For the German situation, the combination of $\mathrm{Z}$ (if there is no known resistance), moxifloxacin (the most effective fluoroquinolone), amikacin (routinely available in German pharmacies), prothionamide and terizidon (a pharmacological improvement of cycloserine; cycloserine is not available in Germany) will be considered for the cost estimation of MDR therapy in our study [9]. 
Derogating from the previous WHO guidelines [12] proposing a treatment duration for MDR-TB patients based on the use of a parenteral agent for a minimum of 6 months and a minimum total length of treatment of 18 months after culture conversion, in the current update [10] an intensive phase of 8 months' duration (including the parenteral agent) is conditionally recommended instead of the previous minimum of 6 months and a total duration of treatment of at least 20 months.

\section{Basic presumptions for calculating costs}

The presumptions for calculating costs are as follows.

1) The responsibility for diagnosis and therapy for primary outpatient treatment or outpatient treatment following initial hospitalisation lies throughout the disease with the private lung specialist or general practitioner (adults) or paediatrician (children). If there were fee schedule positions for different age groups, the respective cheapest position was chosen. According to the number of $231 \mathrm{~TB}$ cases among adults that were extrapulmonary but intrathoracic, the proportion of patients basically to be monitored by pneumologists increased from $80.2 \%$ to $85.8 \%(3,373+231 / 4,201)$.

2) The drug costs were calculated on the basis of the recommended maximum dose for the drugs being administered on a daily basis. The cheapest drugs with the corresponding effective substance were taken according to the 2011 issue of the Rote Liste (German drugs directory). The quadruple therapy including $\mathrm{E}$ is also used in adults for culturally unconfirmed TB. Where drug sensitivity cannot be determined, an unknown $\mathrm{H}$ resistance may exist and $\mathrm{Z}$ will be ineffective in a non-acid milieu. When using $\mathrm{H}, \mathrm{Z}$ and $\mathrm{R}$ without $\mathrm{E}$ in such cases, a de facto $\mathrm{R}$ monotherapy would be in effect, which may result in a selection of R-resistant mutations in large populations of bacteria.

3) Although numerous side-effects can occur throughout therapy, costs for adjuvant medication do not apply: gastrointestinal side-effects from $R$ occur in $\sim 2 \%$ of the cases and can usually be eliminated by having the drug taken after a meal, without antiemetic secondary medication. For short-term chemotherapy with $\mathrm{Z}$ over 2 months, any reduction in uric acid clearance caused by metabolites usually runs without arthralgia or only in the per thousand range, so that accompanying application of uricosuric agents is not indicated [13]. In the therapeutic dose, $\mathrm{H}$ causes peripheral neuropathy induced by pyridoxine deficiency in $\sim 2 \%$ of cases. The low-priced $\mathrm{H}$ preparation calculated here already contains pyridoxine as a prophylactic measure so that no additional costs are incurred [14]. Malfunctions of the liver occur in up to $20 \%$ of the cases with combination therapy (particularly following prior alcoholtoxic damage to the liver) and regularly either recede again spontaneously or after interrupting the therapy. This is not accessible to medication. Neuritis of the optic nerve, with distortion of the sense of colour, occurs extremely rarely under $\mathrm{E}$; this depends on the dose and is normally reversible after stopping the medication and cannot be influenced by therapy. A nephrotoxic effect of amikacin is possible, but reversible; an extremely rare ototoxic effect (disturbed sense of balance or reduced hearing) is often irreversible and cannot be treated. Gastrointestinal side-effects also occur when taking moxifloxacin and prothionamide, as do headaches and sleeplessness. The costs of antiemetic or analgesic concurrent medication are, however, negligible. Psychotic disorders may be a side-effect of terizidone, but these are rare, which is in contrast to those caused by cycloserine.

4) As the rate of hospitalisation (71.2\%) reported for German TB patients in our previous study [4] did not differentiate between any sites of TB, this figure was assumed for patients with extrathoracic as well as intrathoracic TB.

5) In $2009,36.4 \%$ of the TB patients treated solely as outpatients were diagnosed by either microscopy or nucleic acid amplification test assay, with samples taken by bronchial lavage (B. Brodhun; personal communication). Accordingly, that proportion was used for weighting costs in adults with intrathoracic TB. Costs of bronchoscopy were not included for patients with extrathoracic TB or children. Estimates of the frequency with which computer tomography is used as a diagnostic supplement in unclear radiological cases were not available and thus cost data were not included.

6) This calculation adds all attributable costs of state-of-the-art diagnostics and therapy in children and adults as recommended by relevant guidelines/recommendations utilising proportions from routine surveillance data and fixed or already weighted costs. It does not take into consideration either outcomes from clinical trials or different size samples. Confidence intervals are not provided, as their application to this nonprobabilistic model would have been inappropriate.

\section{Direct outpatient costs}

Despite the mandatory diagnosis encryption introduced by law on January 1, 2000, according to ICD-10-SGB V (according to the publication in the Federal Gazette by the Federal Ministry for Health on July 8, 1999) and the subsequently theoretically possible allocation of outpatient costs, there are still no statistical data available for treatment costs by panel doctors in Germany. However, the costs involved in outpatient therapy for TB can still be delimited by a model calculation, as follows:

\section{Monitoring during therapy}

The monitoring of anti-TB therapy described here is closely related. Microbiology sputum tests for primarily microscopically positive TB in the initial phase (three samples for the larger yield) weekly and then every 4 weeks until negative results are obtained [15], i.e. at least five times for a presumed conversion within 8 weeks. Cultures are grown in the initial phase (positive culture results followed by resistance test), then after 4 and 8 weeks (conversion should have occurred by that time) and then once more towards the end of the therapy (verification of successful therapy according to WHO criteria). According to the latest WHO recommendations, MDR-TB patients should be monitored by monthly sputum smear microscopy and culture examination throughout therapy [10]. For patients with extrathoracic $\mathrm{TB}$, it was assumed that only one culture would be performed at baseline.

\section{Material costs of the TST}

The TST licensed for Germany is purified protein derivative RT 23, 2 TU in $0.1 \mathrm{~mL}$ from the Danish State Serum Institute, and distributed by Pharmore Ltd (Ibbenbüren, Germany). The delivered price for 10 glass vials, each containing $1.5 \mathrm{~mL}$ of 
RT 23, is $€ 83.26$. Since droplets always remain in the cannula and the vial, only 10 test doses of 2 TU are withdrawn from the $1.5-\mathrm{mL}$ vials. According to the manufacturer's specifications, opened vials can be used only up to a maximum of $24 \mathrm{~h}$ after the withdrawal of the first dose. Whether only one or the maximum of 10 test doses per vial are used depends on the number of persons tested per day. Consequently, the material costs per TST range from $€ 1.83$ to $€ 18.37$. The mean dose amount of five test doses, with costs of $€ 9.15$ per contact individual, is assumed as the base-case value in the present analysis [16].

\section{Laboratory tests}

In accordance with the DZK guidelines, a broad blood profile is necessary before therapy starts, together with definition of the kidney retention values (creatinine and urea), the liver values (glutamic oxaloacetic transaminase, glutamic pyruvate transaminase, bilirubin and $\gamma$-glutamyl transferase (which is required as alcohol abuse parameter and also allows for differentiation between $\mathrm{H}$-induced hepatitis and $\mathrm{R}$-induced cholangitis in case this value increases as a result of the medication)); it is also advisable to determine uric acid level in adults (as compliance parameter because an increase under $\mathrm{Z}$ is almost certain), together with hepatitis serology (surface antigen of the hepatitis B virus and antibody to the hepatitis B core antigen), as well as HIV serology. The liver values were tested 2-4 weeks after starting the therapy, and every 4 weeks thereafter (bilirubin was not checked if there are no anomalies in the liver parameters in the first test and subsequent checks). The uric acid values were checked only every 4 weeks until $\mathrm{Z}$ was stopped, i.e. altogether only twice in standard therapy if a prior hyperuricaemia was not reported. Blood tests and the renal retention parameters were checked every month through to the end of the therapy, together with checks of the liver values.

The serum level of amikacin in MDR patients was controlled at the end of the first week, and 2 and 6 weeks after starting the therapy (given normal kidney function).

\section{Ophthalmic examination}

Ophthalmic examination was carried out under E before therapy started and usually every 4 weeks, i.e. for a 2-month treatment with E, altogether three times (in the initial phase, and then after 4 and 8 weeks); audiometry testing was carried out in the initial phase and then every 4 weeks during amikacin therapy in MDR patients, 10 times in total.

\section{Radiographs}

Radiographs were carried out in the initial phase, after 4 weeks (to control whether the TB was reacting to the therapy), and after 8 weeks (at the end of the initial therapy as a success assessment). After 8 weeks, radiographic checkups in the fourth and sixth months were sufficient. For patients with extrathoracic $\mathrm{TB}$, only one radiographic examination at baseline was necessary for the exclusion of intrathoracic TB. Further follow-up of patients by chest radiography after the end of treatment was not a matter for this analysis.

\section{Calculations}

The resulting treatment costs were charged to the GKV according to EBM (Einheitlicher Bewertungs-Maßstab) [5] and multiplied by the average number of points for all service types and providers as far as no fixed prices were given. The GKV point value for Germany (bundeseinheitlicher Orientierungspunktwert) in 2011 was $€ 0.035048$. The calculation tables show, separately for primary outpatients and outpatients following primary hospitalisation, the outpatient costs for diagnostics and monitoring (table 1) and treatment (tables 2, 3 and 4), and result in mean case costs for purely outpatient therapy amounting to $€ 1,197.41$ for adults and $€ 1,006.48$ for children (table 5).

The outpatient costs after initial hospitalisation were $€ 749.21$ for adults and $€ 672.66$ for children. The costs for treating MDR-TB amounted to $€ 36,543.22$ for primary outpatients and $€ 27,271.95$ for post-hospitalisation outpatients (for detailed information see online supplementary material).

\section{In-patient costs}

As far as in-patients are concerned, since January 1, 2004, hospital costs are based on the uniform German G-DRG system, which allocates each case to a diagnosis-related group. Under that system, reimbursement of hospital services is no longer based on fixed daily rates for the period of stay, but focuses on the type and severity of the diseases. A calculated base rate for the hospitals in the corresponding federal state is then multiplied by the specific cost weight of a disease, resulting in the proceeds for the hospital providing the treatment. For TB, there are three categories: whilst the costs for E76B cases (with severe complications, hospital stay $<14$ days) and E76C cases (without severe complications, hospital stay $<14$ days) are fixed by multiplying the national base rate (Bundesbasisfallwert) for 2010 of $€ 2,935.78$ by different cost weights depending on their different degree of disease severity (1.022 for E76B and 0.912 for E76C), the cost per day for patients being diagnosed and treated in hospital for $>14$ days (E76A, introduced since 2007) has to be negotiated separately between third-party payers and the respective hospital, and may vary accordingly.

The InEK provides detailed data for TB patients treated for the first time or retreated after relapse in hospitals on its G-DRG browser (G-DRG flat rate catalogue version 2010 data according to §21 Krankenhausentgeltgesetz (German hospital fees act)). Based on a mean per-day reimbursement for those patients of $€ 296.31$ (data not published), the mean hospitalisation cost per standard TB patient was $€ 9,109.13$ and $€ 24,986.89$ per MDR-TB patient (see online supplementary material).

\section{Combined in-patient/outpatient TB costs}

The average combined in-patient/outpatient costs for nonMDR-TB in Germany in 2009 per adult patient was $€ 7361.87$, but was $€ 52,258.84$ for MDR-TB patients (see online supplementary material).

\section{Indirect costs}

From a societal point of view, losses in productivity due to disease, the so called indirect costs, must be included in disease cost estimates. In accordance with the human capital approach, indirect costs represent the production loss for the economy at large caused by absence from the workplace on sick leave. According to the "Hanoverian Consensus" [17], the productivity losses caused by sickness should be evaluated without consideration of differences in the branches of work performed, age or sex ("overall employees"), using the 
TABLE 1 State health insurance system (GKV) medication and technical costs for outpatient therapy

\begin{tabular}{|c|c|c|c|c|c|c|}
\hline Medical services & Points $n$ & Point value cents" & Individual payment $€$ & Frequency & Payment $€$ & $\begin{array}{l}\text { Post-hospital } \\
\text { payment } €\end{array}$ \\
\hline \multicolumn{7}{|l|}{ First doctor's visit (GP or paediatrician) } \\
\hline \multicolumn{7}{|l|}{$\begin{array}{l}\text { Pneumological diagnostics (pulmonary/ } \\
\text { intrathoracic TB) }\end{array}$} \\
\hline Pneumological consultation (EBM 13641) & 570 & 3.5048 & 19.98 & $1\left(0^{+}\right)$ & 19.98 & \\
\hline \multicolumn{7}{|l|}{ For amikacin treatment in MDR-TB } \\
\hline $\begin{array}{l}\text { Audiometry (EBM 09320); ENT code can } \\
\text { also be applied }\end{array}$ & 415 & 3.5048 & 14.54 & $10\left(5^{+}\right)$ & 145.40 & 72.70 \\
\hline Amikacin serum levels EBM 32341 & & & $17.70^{\circ}$ & $3\left(0^{+}\right)$ & 53.1 & \\
\hline \multicolumn{7}{|l|}{ For ethambutol treatment in non-MDR-TB } \\
\hline $\begin{array}{l}\text { Ophthalmological consultation EBM } 06211 \\
\text { (sense of colour test can only be charged } \\
\text { as flat per quarter ) }\end{array}$ & 515 & 3.5048 & 18.05 & & 18.05 & 18.05 \\
\hline \multicolumn{7}{|l|}{ Laboratory services } \\
\hline $\begin{array}{l}\text { Transport fee per case (EBM 40100), } \\
\text { per quarter }\end{array}$ & & & $2.60^{\circ}$ & $3\left(2^{+}\right)\left(\mathrm{MDR}-\mathrm{TB} 6\left(5^{+}\right)\right)$ & 7.8 (MDR-TB 15.6) & 5.2 (MDR-TB 13) \\
\hline HBsAg (EBM 32781) & & & $5.5^{\circ}$ & $1\left(0^{+}\right)$ & 5.5 & \\
\hline $\begin{array}{l}\text { Microscopy test for mycobacteria } \\
\text { (EBM } 32176) \\
\text { NAAT EBM } 32825\end{array}$ & & & $\begin{array}{l}5.60^{\circ} \\
61.40^{\circ}\end{array}$ & $\begin{array}{c}5\left(1^{+}\right)\left(1^{5}\right)\left(1^{f}\right)(\text { MDR-TB } \\
\left.23\left(18^{+}\right)\right) \\
1\left(0^{+}\right)\end{array}$ & $\begin{array}{l}28.0 \text { (MDR-TB 128.8) } \\
\quad 61.40\end{array}$ & $\begin{array}{l}5.6\left(0^{+}\right) \\
\text {(MDR-TB 100.8) }\end{array}$ \\
\hline Culture test for mycobacteria (EBM 32747) & & & $31.7^{\circ}$ & $4\left(1^{f}\right)\left(3^{+}\right)(\mathrm{MDR}-\mathrm{TB}$ & $126.8\left(31.7^{\# \#}\right)$ & $95.1\left(0^{\# \#)}\right.$ \\
\hline $\begin{array}{l}\text { per material } \\
\text { Differentiation of TB bacteria (EBM 32764) } \\
\text { if positive }\end{array}$ & & & $18.9^{\circ}$ & $\begin{array}{c}\left.22\left(18^{+}\right)\right) \\
1\left(0^{5}\right)\end{array}$ & $\begin{array}{l}\text { (MDR-TB 697.4) } \\
18.9\left(0^{5}\right)\end{array}$ & (MDR-TB 570.6) \\
\hline $\begin{array}{l}\text { Resistance definition (EBM 32770) } \\
\text { per mycobacteria type }\end{array}$ & & & $\begin{array}{l}46^{\circ}(9.2 \times 5 \text { different } \\
\text { antibiotics tested })\end{array}$ & $1\left(0^{5}\right)$ & $46\left(0^{5}\right)$ & \\
\hline Creatinine (Jaffe's method) (EBM 32066) & & & $0.25^{\circ}$ & $7\left(5^{+}\right)\left(\right.$MDR-TB $\left.22\left(19^{+}\right)\right)$ & 1.75 (MDR-TB 5.5) & 1.25 (MDR-TB 4.75) \\
\hline Urea (EBM 32065) & & & $0.25^{\circ}$ & $7\left(5^{+}\right)\left(\right.$MDR-TB $\left.22\left(19^{+}\right)\right)$ & 1.75 (MDR-TB 5.5) & 1.25 (MDR-TB 4.75) \\
\hline GPT (EBM 32070) & & & $0.25^{\circ}$ & $8\left(5^{+}\right)\left(\right.$MDR-TB $\left.22\left(19^{+}\right)\right)$ & 2 (MDR-TB 5.5) & 1.25 (MDR-TB 4.75) \\
\hline $\begin{array}{l}\text { Radiograph (EBM 34241; a consultation } \\
\text { cannot be charged) }\end{array}$ & 430 & 3.5048 & $15.07^{\circ}$ & $\begin{array}{c}5\left(3^{+}\right)\left(1^{f}\right)(\text { MDR-TB } \\
\left.12\left(9^{+}\right)\right)\end{array}$ & $\begin{array}{l}75.35\left(15.07^{f}\right) \\
\text { (MDR-TB 180.84) }\end{array}$ & $\begin{array}{c}45.21\left(0^{f}\right) \\
(\text { MDR-TB 135.63) }\end{array}$ \\
\hline
\end{tabular}

GP: general practitioner; EBM: uniform appraisal scale (Einheitlicher Bewertungs-Maßstab); TB: tuberculosis; BAL: bronchoalveolar lavage; MDR: multidrug resistant; ENT: ear, nose and throat; PPD: purified protein derivative; HBsAg: surface antigen of the hepatitis B virus; NAAT: nucleic acid amplification test; anti-HBc: anti-hepatitis C virus; GGT: $\gamma$-glutamyl transferase; GOT: glutamic oxaloacetic transaminase; GPT: glutamic pyruvate transaminase. ${ }^{\#}:$ if no fixed price is stated ("), the average German GKV point value 2011 for all cost types was used; ${ }^{+}$: following primary hospitalisation; ${ }^{\S}$ : if there is noninfectious TB; ${ }^{f}$ : for extrathoracic patients only, one chest radiograph was performed at start of diagnostics; ${ }^{\# \#}$ : controls omitted for noninfectious TB.

average gross income for the period from nonself-employed employment.

The average productivity loss to cover the self-employed is calculated as follows: productivity loss=sick leave days $\times$ (gross income from nonself-employed work/(number of employer-dependent gainfully employed $\times 365$ days)). As more detailed information is not available, an estimate is recommended on the basis of the data provided by the Federal Statistics Department: the mean sick leave duration in 2008 of mandatory members of the AOK (previously mentioned) throughout Germany as a result of TB (ICD-10 A15-A19) was on average 43.368 days $/ 1,286$ cases $=33.7$ days per case [8]. For 2010, the loss in productivity in Germany was considered to be €95.82 (and in 2009, €93.92) per sick leave day [18].

The proportion of those gainfully employed in the mandatory age group (15-64 yrs) was 71.0\% in 2009 [19]. Accordingly, loss of productivity per person ill with TB was $€ 95.82 \times 34$ days (rounded up), multiplied by the proportion of employees in $2009(\times 0.71)=€ 2,313.09$. It should be noted that this figure is a weighted mean and that, in MDR-TB, cases at the individual level, the loss of productivity may be by far higher.

\section{Costs of public health screening for latent TB infection}

According to sections 16 and 25 of the Infection Protection Act (IfSG), the responsibility for diagnosis of latent TB infection 


\begin{tabular}{|c|c|c|c|}
\hline \multirow[t]{2}{*}{ Medication ${ }^{*}$} & \multicolumn{3}{|c|}{ Costs $€$} \\
\hline & $\begin{array}{c}\text { Per day } \\
\text { rounded up }\end{array}$ & Average $e^{\pi}$ & $\begin{array}{l}\text { Post-hospital } \\
\text { stay days }\end{array}$ \\
\hline Rifampicin ${ }^{+}$ & 2.70 & 486.0 & $405.0(150)$ \\
\hline Isoniazid $^{\mathbf{5}}$ & 0.28 & 50.4 & $42.0(150)$ \\
\hline Ethambutolf $f$ & 1.63 & 97.8 & $48.9(30)$ \\
\hline Pyrazinamide & 1.61 & 96.6 & $48.3(30)$ \\
\hline Total & & 730.8 & 544.2 \\
\hline \multicolumn{4}{|c|}{$\begin{array}{l}\text { \#: always based on the smallest pack available for the necessary minimum } \\
\text { period of treatment. The daily therapy costs are calculated from the quotient } \\
\text { between the intake quantity stated in the dosing instructions and the pack } \\
\text { quantity and multiplied by the number of treatment days. }: \text { based on an } \\
\text { average treatment period of } 180 \text { days for isoniazid and rifampicin; } 60 \text { days are } \\
\text { taken for pyrazinamide, ethambutol and streptomycin using the recommended } \\
\text { maximum dose in each case. }{ }^{+}: \text {eremfat } 600-\mathrm{mg} \text { tablet, one tablet taken once a } \\
\text { day as instructed (maximum dose } 600 \mathrm{mg} \text { ). }{ }^{5}: \text { isoniazid } 300-\mathrm{mg} \text { tablet, one } \\
\text { tablet taken once a day as instructed (maximum dose } 300 \mathrm{mg} \text { ). }{ }^{f} \text { : EMB Hefa } \\
400 \text {-mg tablet, four tablets taken once a day as instructed (maximum dose } \\
1,600 \mathrm{mg} \text { ). \#\#: pyrazinamide } 500-\mathrm{mg} \text { tablet, five tablets taken once a day as } \\
\text { instructed (maximum dose } 2,500 \mathrm{mg} \text { ). }\end{array}$} \\
\hline
\end{tabular}

before sending a screened contact to settled pneumologists (i.e. pneumonologists in private practice rather than being hospital based) lies with the public health service. The public health departments to whom each patient suffering from active TB disease has to be reported routinely perform contact investigations according to sections 16 and 25 of the IfSG. Thus, each case of a person with infectious, i.e. culture-confirmed, pulmonary TB disease results in further cost for those contact investigations, the purpose of which is to minimise possible chains of infection. Furthermore, "source tracing" may be carried out in patients with TB who have recently developed

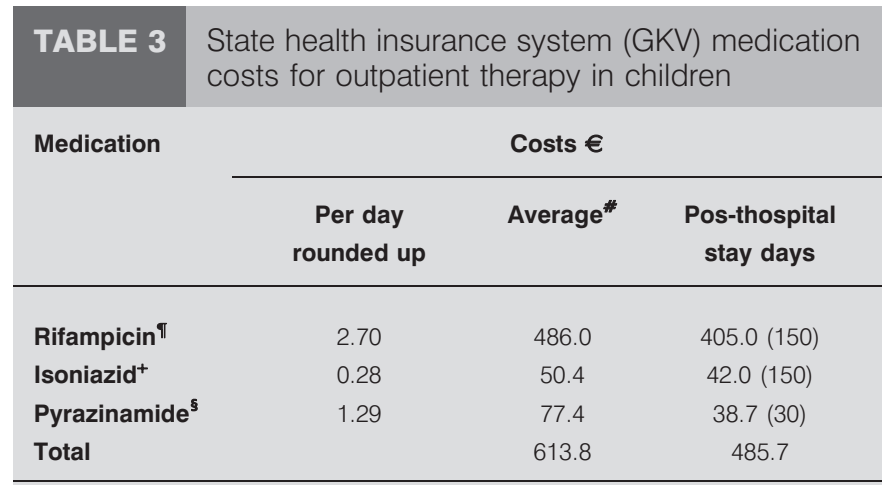

\#: based on an average treatment period of 180 days for isoniazid and rifampicin, and 60 days for pyrazinamide using the recommended maximum dose in each case; $\bullet$ : eremfat 600 -mg tablet one tablet taken once a day as instructed (maximal dose $600 \mathrm{mg}$ ) ; ${ }^{+}$: isoniazid 300-mg tablet, one tablet taken once a day as instructed (maximal dose $300 \mathrm{mg}$ ); ${ }^{\S}$ : pyrazinamide 500-mg tablet, four tablets taken once a day as instructed (maximal dose 2,000 mg).

\begin{tabular}{|c|c|c|c|}
\hline TABLE 4 & \multicolumn{3}{|c|}{$\begin{array}{l}\text { State health insurance system (GKV) medication } \\
\text { costs for outpatient therapy in adults with } \\
\text { multidrug-resistant tuberculosis }\end{array}$} \\
\hline \multirow[t]{2}{*}{ Medication } & \multicolumn{3}{|c|}{ Costs $€$} \\
\hline & $\begin{array}{c}\text { Per day } \\
\text { rounded up }\end{array}$ & Average $^{\#}$ & $\begin{array}{l}\text { Post-hospital stay } \\
\text { minus } 86 \text { days }\end{array}$ \\
\hline Amikacin $\rrbracket$ & 71.22 & 17092.80 & 10967.88 \\
\hline Prothionamide $^{+}$ & 3.94 & 2363.04 & 2025.16 \\
\hline Moxifloxacin ${ }^{5}$ & 7.04 & 4224.00 & 3618.56 \\
\hline Pyrazinamide ${ }^{f}$ & 1.61 & 966.00 & 827.54 \\
\hline Terizidone $\#$ \# & 17.28 & 10368.00 & 8881.92 \\
\hline Total & & 35013.84 & 26321.06 \\
\hline
\end{tabular}

\#: based on an average treatment period of 600 days for pyrazinamide, terizidone, moxifloxacin and prothionamide; 240 days are taken for amikacin using the recommended maximum dose in each case. $"$ : Amikacin Fresenius infusion bottle $500 \mathrm{mg}$ per $100 \mathrm{~mL}$, two infusions administered once a day as instructed (maximal dose 1,000 mg). +: Ektebin Riemser 100-mg tablet 100 (N3), four tablets taken once a day as instructed (maximal dose 1,000 mg). ${ }^{\S}$ : Avalox 400-mg tablet, one tablet taken once a day as instructed (maximal dose $400 \mathrm{mg}$ ). ${ }^{f}$ : Pyrazinamide 500-mg tablet, five tablets taken once a day as instructed (maximal dose $2.5 \mathrm{~g}$ ). \#\#: Terizidon 250-mg capsules, $2 \times 2$ capsules taken as recommended (maximal dose $2 \times 500 \mathrm{mg}$ ).

the infection, such as tuberculous pleuritis or meningitis, and/ or cases in children.

The mean cost of $€ 52.05$ per person for tracing a source and $€ 74.30$ per qualified contact person for infectious TB patients have been recently documented in a cost study [16] based on a dual step testing approach (TST first, followed, if positive, by a highly specific interferon $-\gamma$ release assay as confirmation). Both cost figures have to be added to the cost of treatment of the disease itself, irrespective of whether subsequent preventative chemotherapy will be performed in infected contacts of infectious TB patients.

Based on statistics from the Fingerprinting Study of the German Central Committee Against TB [20], in which 2,562 patients were involved, the weighted total costs arising per TB case due to contact investigations from the public heath perspective were $€ 921.80$ (see online supplementary material).

\section{Cost of rehabilitation measures}

The cost of rehabilitation measures for TB are not negligible; in 2009,113 subsequent therapies were performed for all forms of TB taken together (ICD-10 A15-19) [21], i.e. for $2.5 \%$ of all TB cases, with an average duration of 24 days. The daily cost per rehabilitation facility in 2009 was $€ 123$ [22], resulting in costs of $€ 2,952$ per patient; thus, a further treatment cost per patient of $€ 2,952 \times 0.025=€ 73.8$ must be added.

\section{Costs for productivity losses caused by deaths}

The mortality rate for TB of 154 deaths in 2009 (3.5\% of all 4,444 cases of the disease [4]) is not low. However, the share of elderly (aged $\geqslant 65 \mathrm{yrs}$ ) among the deceased amounted to $74.1 \%$ [23], for whom it appears to make little sense in calculating the loss of productivity due to the very low gainful 


\begin{tabular}{|c|c|c|c|}
\hline \multirow[t]{3}{*}{ TABLE 5} & \multicolumn{3}{|c|}{$\begin{array}{l}\text { Age-dependent direct treatment costs for } \\
\text { tuberculosis (TB) }\end{array}$} \\
\hline & & \multicolumn{2}{|c|}{ Age group yrs } \\
\hline & & $0-<15$ & $\geqslant 15$ \\
\hline \multicolumn{4}{|c|}{ Hospital treatment } \\
\hline Mean hosk & talisation rate \% & 71.2 & 71.2 \\
\hline Mean reim & ursement per case $€$ & 9109.13 & 9109.13 \\
\hline Culture co & firmation \% & 80.5 & 80.5 \\
\hline Mean hosp & tal stay days & 30.17 & 30.17 \\
\hline Pneumolog & cal monitoring in adults \% & & 85.8 \\
\hline \multicolumn{4}{|c|}{$\begin{array}{l}\text { Primary outpatient therapy } \\
\text { (adults) } €\end{array}$} \\
\hline Intrathorac & TB & & 1223.32 \\
\hline Extrathorac & c TB & & 1040.88 \\
\hline Weighted & verage & & 1197.41 \\
\hline \multicolumn{4}{|c|}{$\begin{array}{l}\text { Post-hospital outpatient therapy } \\
\text { (adults) } €\end{array}$} \\
\hline Intrathorac & TB & & 767.15 \\
\hline Extrathorac & c TB & & 640.88 \\
\hline Weighted & verage & & 749.21 \\
\hline \multicolumn{4}{|c|}{$\begin{array}{l}\text { Primary outpatient triple therapy } \\
\text { (children) } €\end{array}$} \\
\hline Intrathorac & TB & 1036.51 & \\
\hline Extrathorac & c TB & 825.03 & \\
\hline Weighted & verage & 1006.48 & \\
\hline \multicolumn{4}{|c|}{$\begin{array}{l}\text { Posthospital outpatient triple } \\
\text { therapy (children) } €\end{array}$} \\
\hline Intrathorac & TB & 690.60 & \\
\hline Extrathorac & c TB & 564.33 & \\
\hline Weighted & verage & 672.66 & \\
\hline \multicolumn{4}{|c|}{$\begin{array}{l}\text { Primary outpatient MDR-TB patients } \\
\text { (adults) } €\end{array}$} \\
\hline Intrathorac & TB & & 36688.08 \\
\hline Extrathorac & c TB & & 35667.97 \\
\hline Weighted & verage & & 36543.22 \\
\hline \multicolumn{4}{|c|}{$\begin{array}{l}\text { Posthospital outpatient MDR-TB } \\
\text { patients (adults) } €\end{array}$} \\
\hline Intrathorac & TB & & 27386.55 \\
\hline Extrathorac & c TB & & 26579.52 \\
\hline Weighted & verage & & 27271.95 \\
\hline \multicolumn{4}{|c|}{$\begin{array}{l}\text { Combined in-patient/outpatient } \\
\text { costs } €\end{array}$} \\
\hline Standard $T$ & $B$ adults & & 7363.99 \\
\hline Standard $T$ & 3 children & 7299.73 & \\
\hline MDR-TB & dults only) & & 52258.84 \\
\hline
\end{tabular}

MDR: multi-drug resistant. age groups ages $<65$ yrs. Thus, costs for productivity losses due to death in TB patients were not considered in this study.

\section{Intangible costs}

Evaluation of the intangible costs would require a differentiated, prospective survey with a specific TB-related instrument for measuring the quality of life. It is a known fact that the general instruments for measuring the quality of life (e.g. qualityadjusted life years, the Nottingham Health Profile and EuroQol) are not very sensitive to short-term changes in the state of health, such as those that occur in the various stages of the disease and during therapy for lung $\mathrm{TB}$, with regard to the highly differing risk populations in the various countries with low TB incidence [26]. However, to our knowledge, no such instrument has yet been published.

\section{Total of costs per TB case}

Taking all costs together, the mean cost in adults per TB case is $€ 7,931.02$ (treatment costs including 1.4\% MDR-TB cases) plus $€ 73.8$ (rehabilitation costs) plus $€ 2,313.09$ (loss of productivity) plus $€ 921.80$ (mandatory contact tracing), adding up to a total of $€ 11,239,71$ per person.

\section{DISCUSSION}

Since 2000, published data on costs of TB disease in developed countries are sparse, usually consisting of brief summarised presentations, which vary considerably in their conclusions. ATUN et al. [27] calculated the mean cumulative cost of treating a TB case over 3 yrs to be US\$886 in Russia. Most published data about direct and/or indirect costs of TB still come from the USA. MANCUSO et al. [28] assigned US $\$ 17,869$ as the mean cost for a hospital episode occurring in 2009 in the US, but did not provide a hospitalisation rate for TB patients. On the basis of a questionnaire, SCHWARTZMAN et al. [29] estimated the indirect costs (due to 2 weeks of lost duty time) for a TB patient in the USA to be US\$2,262 in 2003. Holland et al. [30] calculated the total costs per active TB case for a 6-month treatment to be as high as US\$13,000, and US $\$ 13,783$ for a 9month treatment (updated to the 2011 US\$ rate). In a more detailed overview from PORCO et al. [31], treatment costs amount to US\$38,429, but are probably overestimated due to unweighted inclusion of costs for a hepatitis hospital stay of US\$10,662 per patient. DIEL et al. [32] ascertained weighted mean costs of $€ 14,750$ for treating pulmonary $\mathrm{TB}$ in Switzerland in 2006; in contrast, POORAN et al. [33] estimated an amount of only $€ 7,468(£ 7,620)$ for treatment in the UK (updated in 2008). In Japan, KowADA et al. [34] estimate treatment costs of US\$15,775.

Full transparency on the local costs of TB disease is a prerequisite to a debate on the effectiveness of preventive measures against TB to be taken by the respective healthcare system. Although our study provides a breakdown of costs that would be theoretically incurred in treating a typical case of TB disease in Germany, it probably underestimates the real costs of TB. First of all, it has been recommended to extend the continuation period and/or to administer additional first-line drugs or fluoroquinolones in cases of single drug resistance [9]. Furthermore, E should be continued in the continuity phase in TB patients with relapses following prior disease and/or in those coming from foreign countries with higher $\mathrm{H}$ resistance, if 
resistance testing is not possible. This helps to avoid secondary $\mathrm{R}$ resistance, given unknown primary $\mathrm{H}$ resistance [9].

Such discretionary acts, however, were not taken into consideration; although 27 countries with high MDR-TB burden are known [35], there is no available data on frequency of respective resistance patterns or on patients suspect for unknown primary $\mathrm{H}$ resistance in Germany to be covered with cost estimates. As the treatment of MDR-TB may be a very individual one according to resistance patterns, the cost in a given case may differ from that of our exemplary drug schedule. Nevertheless, due to the low number of MDR cases, that fact will not dramatically influence the total average costs per TB case. The limited relevance and/or difficulty of calculating productivity losses from TB lethality addressing primarily older patients and/and or patients with previous medical injuries who are in many cases not available to the labour market has already been pointed out above.

Although other lung diseases, such as chronic bronchitis (with estimated annual costs of $€ 4$ billion) or bronchial asthma (€2.1 billion), account for clearly higher aggregated disease costs of $>€ 24$ billion [36], the most recently available case costs calculated here for Germany classify TB as an acute disease of economic significance.

Our comprehensive analysis includes, for the first time, costs for MDR-TB and public health costs for contact investigations. However, in comparison with the cost study of the year 2004 [3], in which the mean combined in-patient/outpatient costs ranged from $€ 14,301$ (adults) to $€ 16,634$ (children), the costs have clearly decreased. There are several reasons for this surprising development: first, the proportion of patients treated in hospitals was significantly reduced in comparison with 2004 by about $9 \%$ (from $80.0 \%$ to $71.2 \%$ ). Given hospital treatment, the length of hospitalisation was also greatly reduced from a mean of 50 (actual 49.6) days to 30 (actual 30.17) days. Thus, purely outpatient therapy has apparently increased by about one-third, with much lower direct costs due to omitting the considerable stay in hospital amounting on average to 30 days.

When considering sickness benefit costs paid by insurance policies, the average number of days missed from work due to TB was a mean of 34 (actual 33.7) days and, in our update, was so low that the prerequisites of receiving that payment (days off work extending to 42 days) was in general not fulfilled, whilst in 2004 sickness benefit payments of $>€ 2,000$ $(€ 2,087.83)$ had to be considered. This is in line with the lower indirect costs (loss of productivity), with 31 days (33.7 instead of 64.6 days) fewer to be considered.

With respect to cost estimates of TB disease, special attention must be given to the development of the number of MDR-TB cases in the future, which actually contributed to only $1.4 \%$ of all cases in Germany but have already contributed to $8.5 \%$ ( $€ 672.22$ of the total of $€ 7,931.02$ treatment costs). According to our calculation of average costs for a TB case of $€ 11,239.71$, at present the total annual costs due to TB disease in Germany in 2009 add up to $€ 49,959,271.24$.

It is noteworthy that only the costs of $\mathrm{TB}$ patients free of complications were calculated, and among MDR-TB cases, minimum costs based on relatively low-priced drugs that meet the requirements of the drug set proposed by the WHO, were used. As very expensive drugs, such as linezolide, may be necessary in individual cases to address a more limited range of drug susceptibility, our calculation must be understood to assume the lowest plausible drug therapy costs. This figure may dramatically change when treating extensively drug-resistant (XDR) TB, for which costs of $>€ 170,000$ may arise [37], although to date very few cases have occurred (in a German survey, seven XDR-TB cases were identified in the 3-yr period of 2004-2006) [38]. Three further exercises are required to fully cover the impact of MDR-TB costs in our model: 1) An analysis of the treatment needed for different patient types, based on each single resistance pattern; 2 ) the determination of a representative distribution of patient types; and 3) a Monte Carlo analysis. As answering these questions was beyond the scope of our study, it remains an important task for the future.

\section{SUPPORT STATEMENT}

The study was supported by the North German Respiratory Society.

\section{STATEMENT OF INTEREST}

None declared.

\section{ACKNOWLEDGEMENTS}

Many thanks to B. Brodhun (Robert Koch Institute, Berlin, Germany), who provided very helpful special evaluations of epidemiological surveillance data.

\section{REFERENCES}

1 World Health Organization. Global tuberculosis control: WHO report 2011. Geneva, Switzerland, 2011.

2 World Health Organization. 2011/2012 Tuberculosis Global Facts. Geneva, Switzerland, 2011.

3 Diel R, Rappenhöner B, Schaberg T. The cost structure of lung tuberculosis in Germany. Eur J Health Econ 2004; 5: 243-251.

4 Robert Koch Institut. Bericht zur Epidemiologie der Tuberkulose in Deutschland für 2009. [Report on the epidemiology of tuberculosis in Germany in 2009.] Berlin, 2011.

5 Kassenärztliche Bundesvereinigung, Einheitlicher Bewertungsmaßstab [EBM], Stand 1. October 2011. www.kbv.de/8156.html. Date last accessed: March 21, 2012.

6 Institut für das Entgeltsystem im Krankenhaus. Definitions Handbuch 2011. G-DRG Version 2011. Siegburg, InEK, 2011.

7 InEK - Institut für das Entgeltsystem im Krankenhaus. Datenveröffentlichung gem. § 21 KHEntgG: www.g-drg.de/cms/content/ view/full/2877. Date last accessed: March 21, 2012.

8 Gesundheitsberichterstattung des Bundes. Arbeitsunfähigkeit bei AOK - Pflichtmitgliedern ohne Rentner (Arbeitsunfahigkeitsfälle und Arbeitsunfahigkeitstage), 2008.

9 Schaberg T, Bauer T, Castell S, et al. [Recommendations for therapy, chemoprevention and chemoprophylaxis of tuberculosis in adults and children. German Central Committee against Tuberculosis (DZK), German Respiratory Society (DGP)]. Pneumologie 2012; 66: 133-171.

10 Falzon D, Jaramillo E, Schünemann HJ, et al. WHO guidelines for the programmatic management of drug-resistant tuberculosis: 2011 update. Eur Respir J 2011; 38: 516-528.

11 EuroTB (CESES/KNCV) and the national coordinators for tuberculosis surveillance in the WHO European Region (1998). Surveillance of tuberculosis in Europe Report on tuberculosis cases notified in 1996. http://ecdc.europa.eu/en/publications/ 
Publications/SUR_TB_EuroTB_EuroTB_Annual_report_1996.pdf Date last accessed: May 15, 2012.

12 World Health Organization. Guidelines for the Programmatic Management of Drug-Resistant Tuberculosis, Emergency Update 2008 (WHO/HTM/TB/2008.402). Geneva, Switzerland.

13 Zierski M. Pharmakologie, Toxikologie und Anwendung von Pyrazinamid [Pharmacology, toxicology and clinical use of pyrazinamide]. Prax Klin Pneumol 1981; 35: 1075-1105.

14 Zierski M, Rotermund C. Isoniazid - Wesentliches und Neues. Prax Klin Pneumol 1984; 38: 201-216.

15 Schlossberg D. Current therapy of infectious disease. 2nd Edn. Mosby, St. Louis, 2001; pp. 565.

16 Diel R, Nienhaus A, Lange C, et al. Cost-optimization of screening for latent tuberculosis in close contacts. Eur Respir J 2006; 28: 35-44.

17 Graf von der Schulenburg JM, Greiner W, Jost F, et al. German recommendations on health economic evaluation: third and updated version of the Hanover Consensus. Value Health 2008; 11: 539-544.

18 Statistisches Bundesamt. Volkswirtschaftliche Gesamtrechnungen; Fachserie 18, Reihe 1.2 2. Vierteljahr 2011, 2.15 Arbeitnehmerengelt je Arbeitnehmer. Wiesbaden, Germany, 2011.

19 Statistisches Bundesamt: Ergebnisse des Mikrozensus: Jahresdurchschnittswerte.

20 Diel R. Schwierigkeiten und Schwachpunkte der TB-Kontrolle in Deutschland. 51. Kongress der Deutschen Gesellschaft für Pneumologie und Beatmungsmedizin, Hannover, Germany, 2010.

21 Verband Deutscher Rentenversicherungsträger-VDR Statistik Rehabilitation. Durchschnittliche Pflegetage bei stationären Behandlungen zur medizinischen Rehabilitation und sonstigen Leistungen zur Teilhabe für Erwachsene in der Gesetzlichen Rentenversicherung (Anzahl).

22 Clade H. Rehabilitation: Steigender Bedarf, moderates Wachstum. Rheinisches Ärzteblatt 2010; 64: 23-25.

23 Statistisches Bundesamt, Bonn (2011). Todesursachen in Deutschland 2009. Fachserie 12 Reihe 4: 2.1 Sterbefälle 2009 nach ausgewählten Todesursachen, Altersgruppen und Geschlecht.

24 Diel R, Schneider S, Meywald-Walter K, et al. Epidemiology of tuberculosis in Hamburg, Germany: long-term population-based analysis in applying classical and molecular epidemiological techniques. J Clin Microbiol 2002; 40: 532-539.

25 Diel R, Niemann S. Outcome of tuberculosis treatment in Hamburg: a survey 1997-2001. Int J Tuberc Lung Dis 2003; 7: 124-131.
26 Hanson K. Measuring Up: Gender, Burden of Disease, and Priority Setting Techniques in the Health Sector. Working Paper Series 99. 12, Harvard Center for Population and Development Studies, Cambridge, 1999.

27 Atun RA, Samyshkin Y, Drobniewski F, et al. Costs and outcomes of tuberculosis control in the Russian Federation: retrospective cohort analysis. Health Policy Plan 2006; 21: 353-364.

28 Mancuso JD, Niebuhr DW, Frick KD, et al. Cost-Effectiveness analysis of targeted and sequential screening strategies for latent tuberculosis. Int J Tuberc Lung Dis 2011; 15: 1223-1330.

29 Schwarzmann K, Oxlade O, Barr RG, et al. Domestic returns from investment in the control of tuberculosis in other countries. N Engl J Med 2005; 353: 1008-1020.

30 Holland DP, Sanders GD, Hamilton CD, et al. Potential economic viability of two proposed rifapentine-based regimens for treatment of latent tuberculosis infection. PLoS One 2011; 6: e22276.

31 Porco TC, Lewis B, Marseille E, et al. Cost-effectiveness of tuberculosis evaluation and treatment of newly-arrived immigrants. BMC Public Health 2006; 6: 157.

32 Diel R, Wrighton-Smith P, Zellweger JP. Cost-effectiveness of interferon- $\gamma$ release assay testing for the treatment of latent tuberculosis. Eur Respir J 2007; 30: 321-332.

33 Pooran A, Booth H, Miller RF, et al. Different screening strategies (single or dual) for the diagnosis of suspected latent tuberculosis: a cost effectiveness analysis. BMC Pulm Med 2010; 10: 7.

34 Kowada A, Deshpande GA, Takahashi O, et al. Cost effectiveness of interferon-gamma release assay versus chest X-ray for tuberculosis screening of BCG-vaccinated elderly populations. Mol Diagn Ther 2010; 14: 229-236.

35 World Health Organization. Tuberculosis country profiles. www. who.int/entity/tb/country/data/profiles/en/index.html Date last accessed: March 21, 2012.

36 Konietzko N, Fabel H. Weißbuch Lunge 2005. 3. Revised edition. Stuttgart, Thieme, 2005.

37 Blaas SH, Muetterlein R, Weig J, et al. Extensively drug-resistant tuberculosis in a high-income country: a report of four unrelated cases. BMC Infect Dis 2008; 8: 60.

38 Eker B, Ortmann J, Migliori GB, et al. Multidrug- and extensively drug resistant tuberculosis, Germany. Emerg Infect Dis 2008; 14: 1700-1706. 